\title{
Sistemas de ferro-enxofre
}

\author{
- das Geociências às Biociências
}

São vários os minerais e as proteínas em que o Fe e o S estão ligados químicamente. Pelas características dessas estruturas foi sugerida a possibilidade deste tipo de proteínas ter sido formado na sequência da participação de alguns minerais em reacções pré-bióticas, os quais tendo incorporado alguns produtos formados originaram estruturas mais complexas. Nos desenvolvimentos posteriores as moléculas formadas passaram a participar em funções biológicas que se devem ter diversificado como consequência da pressão da Evolução.

\section{Introdução}

Quem estudou os aspectos básicos da Bioquímica conhece certamente uma variedade de proteínas contendo no seu centro activo sistemas envolvendo a coordenação do enxofre ao ferro. Este tipo de proteínas são comuns em todos os organismos e participam em diversas funções metabólicas [1]. É também sabido que o $\mathrm{Fe}$ e o S são elementos abundantes na crusta terrestre sendo conhecido um número significativo de minerais de cuja composição fazem parte estes dois elementos.

Far-se-á neste trabalho alguns comentários sobre os sistemas de Fe-S do ponto de vista minerológico, alguns aspectos relativos à sua química, de seguida sobre a sua ocorrência e suas funções nos organismos vivos e depois apresentam-se hipóteses da sua existência nos seres vivos a partir da evolução de formas minerais. Estas hipóteses sugerem a importância de alguns metais nos sistemas biológicos ser anterior à emergência da Vida na Terra.

\section{Minerais de ferro-enxofre}

O número de minerais contendo Fe e S é superior a 110 [2], todavia a grande maioria não contém apenas estes dois elementos. Na Tab. 1 apresentam-se os
5 minerais contendo apenas Fe e S e algumas das suas características.

Refira-se ainda, um exemplo, que contém também outros elementos quími$\mathrm{cos}$, a violarita, que inclui $\mathrm{Ni}$, com a fórmula $\mathrm{FeNi}_{2} \mathrm{~S}_{4}$ e se forma em ambientes hidrotermais [2]. Este exemplo foi escoIhido porque o Ni pode ter sido importante na química pré-biótica, ver parte final deste trabalho.

A formação destes minerais está dependente de vários factores, como sejam o $\mathrm{pH}$, as concentrações relativas dos iões envolvidos e o potencial de oxidação-redução do meio. A formação de sulfuretos está dependente da existência

Tabela 1 Algumas características do minerais contendo apenas Fe e S [2]

\begin{tabular}{|c|c|c|}
\hline Designação & Fórmula química & Observações \\
\hline Greigita & $\mathrm{Fe}_{3} \mathrm{~S}_{4}$ & $\begin{array}{l}\text { Algumas bactérias de ambientes anóxicos também a sintetizam e a usam } \\
\text { como sistema de orientação devido às suas características magnéticas [3] }\end{array}$ \\
\hline Pirita ${ }^{a)}$ & $\mathrm{FeS}_{2}$ & $\begin{array}{l}\text { É um dos sulfuretos mais abundantes na Terra, tem origem magmática, me- } \\
\text { tamórfica e sedimentar, e pode ocorrer em depósitos hidrotermais }\end{array}$ \\
\hline Marcasita & $\mathrm{FeS}_{2}$ & $\begin{array}{l}\text { É um polimorfo da pirita, isto é, têm a mesma composição mas uma estrutu- } \\
\text { ra diferente }\end{array}$ \\
\hline Pirrotita & $\mathrm{Fe}_{(1-\mathrm{X})} \mathrm{S} \quad(\mathrm{X}=0-0,17)$ & Está muito espalhada em rochas ígneas e metamórficas \\
\hline Troilita & FeS & $\begin{array}{l}\text { Foi apenas identificada em vários meteoritos e pode ser constituinte do nú- } \\
\text { cleo terrestre }\end{array}$ \\
\hline
\end{tabular}

* Centro de Química Estrutural, Complexo 1, Instituto Superior Técnico, Av. Rovisco Pais, 1, 1049-001, Lisboa (pcd1950@ist.utl.pt) 
de um ambiente redutor, dado que em meio oxidante aquele anião se converteria em sulfato. Como a atmosfera primitiva terrestre tinha um carácter mais redutor a génese de minerais contendo sulfuretos foi favorecida nesse período da história terrestre.

\section{Química dos sistemas de ferro-enxofre ${ }^{1}$}

Embora compostos químicos contendo sistemas de coordenação do S ao Fe tenham tido desenvolvimentos autónomos, este tipo de química também se tem inspirado nas estruturas que ocorrem nos seres vivos. A síntese de compostos com analogias com o centro activo das proteínas de Fe-S começou no início da década de setenta do século passado. A variedade de compostos preparados é grande tendo as sínteses sido feitas em diversos solventes incluindo água. Um conhecimento maior deste tipo de compostos tem dado informações sobre os sistemas biológicos, tendo também os desenvolvimentos na área permitido um aprofundamento da química de coordenação envolvendo o Fe e o S e facilitaram aplicações a outros elementos químicos, incluindo a coordenação de átomos ao Fe que não ocorrem nos sistemas biológicos, como é o caso do $\mathrm{P}$, assim como de ligandos não biológicos, caso de diversos tióis orgânicos, e ainda a presença nos agregados de átomos metálicos inexistentes com essa coordenação química nos sistemas biológicos, como seja o Co [5].

\section{Sistemas de ferro-enxofre nos organismos $^{2}$}

\section{Suas características e suas funções}

Como já foi referido, sistemas com proteínas contendo Fe e S foram identificados em todo o tipo de organismos. Estas proteínas participam em diversas funções, salientando-se os processos de transferência electrónica, em enzimas, actuam como sensores do stresse oxidativo e podem ter uma componente estrutural em metalobiomoléculas. Estão envolvidas em reacções de grande relevância para os organismos vivos, como na fotossíntese, na fixação do diazoto (fundamental na biossíntese das moléculas contendo azoto), nas cadeias respiratórias, etc. Foram identificadas mais de 120 proteínas de Fe-S diferentes, as quais raramente ocorrem no espaço extra-celular, sendo as identificadas nas plantas e nos microrganismos solúveis em água, enquanto as dos mamíferos são membranares.

Na maioria dos casos o ferro e o enxofre formam agregados (contendo mais do que um átomo de $\mathrm{Fe}$ com átomos de S em ponte, ver Fig. 1) e apresentam usualmente a composição $\mathrm{Fe}_{n} \mathrm{~S}_{\mathrm{m}}$ com $n=m=2$ ou 4 . A coordenação ao $\mathrm{Fe}$ pode ser feita por resíduos de cisteína, mas também por enxofre inorgânico. Existem excepções no tipo de coordenação nos agregados, como nas designadas proteínas de Rieske, em que outros resíduos de aminoácidos participam na coordenação ao centro metálico (no caso referido histidina). A variação do estado de oxidação do Fe, com a manutenção da estabilidade da estrutura, justifica a presença destas proteínas em vários processos biológicos.
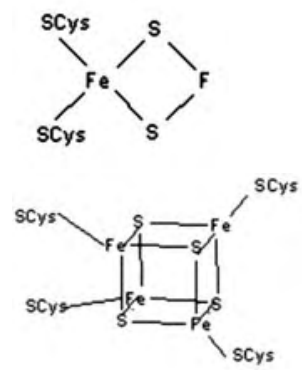

Figura 1 Representação esquemática dos agregados de $\mathrm{Fe}$-S constituintes de proteínas (SCys é um resíduo de cisteína); $\mathrm{Fe}_{2} \mathrm{~S}_{2}$ em cima

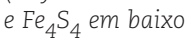

Refiram-se ainda as proteínas de Fe-S dessulforredoxina e rubredoxina que não contêm agregados. Estas duas proteínas participam em processos de transferência electrónica em bactérias, sendo nestes casos o centro metálico mononuclear com uma coordenação tetraédrica feita por quatro átomos de $\mathrm{S}$ provenientes de quatro resíduos de císteina, ver Fig. 2.

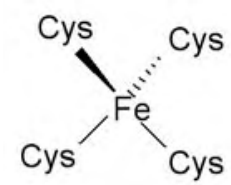

Figura 2 Representação esquemática do centro activo da dessulforredoxina e da rubredoxina

As proteínas envolvidas nos processos de transferência electrónica têm uma massa molecular inferior a 20kDa e apresentam propriedades electroquímicas muito versáteis com uma gama de potenciais de oxidação-redução ampla que varia entre mais de $+400 \mathrm{mV}$ e menos de $-600 \mathrm{mV}$.

No caso das enzimas a sua grande maioria está envolvida em reacções de oxidação-redução (por isso pertencem à classe das óxido-redutases). Nesta classe são conhecidas enzimas que podem ter agregados constituídos por um número de átomos de Fe e $\mathrm{S}$ superiores a 4, como é o caso da nitrogenase, assim como podem incluir, além destes elementos, outros, o que ocorre, por exemplo, tanto na nitrogenase, como na hidrogenase, ver Fig. 3.

$$
\text { OC.... Cys Cys }
$$

Figura 3 Representação esquemática do centro activo da hidrogenase contendo $\mathrm{Fe}$ e Ni; Cys, Cisteína; X, não identificado

Uma outra enzima, pertencente a uma classe diferente (a das liases) e muito relevante no metabolismo é a aconitase que participa no ciclo do ácido cítrico e aí o agregado $\mathrm{Fe}_{4} \mathrm{~S}_{4}$ tem um comportamento de ácido de Lewis, activando o substrato. Na forma inactiva esta enzima perde um dos átomos de Fe do agregado. Esta enzima pode estar envolvida na actividade reguladora de ma-

\footnotetext{
${ }^{1}$ Recomenda-se a referência [5] a quem queira aprofundar o assunto.

2 Para um aprofundamento do tema sugere-se a consulta das referências [1] e [6].
} 
nutenção do ADN mitocondrial. Outras enzimas da mesma família têm diversas funções e podem regular a captura e o metabolismo celular do ferro nos vertebrados, como é o caso da IRP-1, (do inglês, Iron Regulator Protein) que ocorre no citoplasma, o que não é comum nos eucariotas, em sistemas de Fe-S. São conhecidos ainda outros casos na classe das transferases, como a biotina sintase, que está envolvida no passo final da síntese da biotina participando numa reacção radicalar, sendo um dos agregados, $\mathrm{Fe}_{4} \mathrm{~S}_{4}$, essencial para gerar radicais, e um outro, $\mathrm{Fe}_{2} \mathrm{~S}_{2}$, a fonte provável de $\mathrm{S}$ necessário na formação da biotina. Refira-se ainda que a grande maioria das enzimas contendo agregados de Fe-S ocorre apenas em bactérias, uma indicação da sua ancestralidade em termos da evolução, o que pode também ser concluído do facto que algumas delas têm como substratos moléculas consideradas componentes da atmosfera primordial da Terra, como o $\mathrm{CO}$ e - $\mathrm{H}_{2}[1,6]$. Os organismos superiores podem nalgumas situações ter optado por outro tipo de soluções nos elementos usados no centro activo de muitas das suas enzimas porque o seu metabolismo se desenvolveu num ambiente oxigenado em que o uso de agregados de Fe-S não seria tão eficaz para essas funções.

Proteínas contendo agregados $\mathrm{Fe}_{4} \mathrm{~S}_{4}$ fazem também parte de enzimas envolvidas na reparação do ADN [7].

\section{Os modelos químicos versus os sistemas biológicos}

Os desenvolvimentos efectuados na síntese dos compostos de Fe-S ajudaram nalgumas situações a um melhor conhecimento dos sistemas biológicos contendo estes dois elementos. Quando as proteínas de Fe-S foram descobertas e caracterizadas alguns cientistas afirmaram que seria impossível conterem Fe dado que os resultados obtidos por espectroscopia de ressonância paramagnética electrónica não eram justificáveis com base na presença do metal; porém, a síntese de modelos permitiu a confirmação da presença de Fe neste grupo de proteínas. Todavia, nem sempre os modelos químicos deram informações que fossem adequadas aos sistemas biológicos e no caso do agregado contendo também Mo da nitrogenase os modelos revelaram-se errados quando foi determinada a estrutura dessa componente por difracção de raios-X [1].

\section{Alguns aspectos sobre a génese das proteínas contendo $\mathrm{Fe}^{-\mathrm{S}^{3}}$}

As proteínas contendo agregados de Fe-S não se formam espontaneamente nos organismos e é necessária uma maquinaria complexa para a sua biogénese. $\mathrm{Na}$ actualidade são conhecidos três sistemas biossintéticos diferentes, mas todos têm alguns aspectos comuns [8]. Um deles, o ISC (do inglês, Iron-Sulfur Cluster), é o mais geral em termos do tipo de organismos e tem grandes analogias desde as bactérias até aos eucariotas superiores [9].

As plantas, como é sabido, têm a dupla função da respiração e da fotossíntese, e como ambos os processos metabólicos requerem quantidades significativas de proteínas contendo Fe-S, a biogénese destas dá-se também nos cloroplastos e não só nos mitocôndrios como na generalidade dos outros eucariotas $[9,10]$. Todavia um caso curioso é o da Giardia intestinalis, um protozoário intestinal patogénico muito espalhado que é responsável por centenas de milhares de casos de diarreia todos os anos. Estes microrganismos não contêm mitocôndrios, admitindo-se que estes tenham desaparecido no processo de evolução da espécie, mas a função de biogénese das proteínas de Fe-S é efectuada noutros organelos designados mitossomas $[10,11]$. Este caso não é único e indica a tendência da biogénese das proteínas de Fe-S nos organelos dos eucariotas. Tendo em conta que tanto os cloroplastos, como os mitocôndrios são provenientes da endosimbiose de bactérias, e sabendo-se da existência de raízes comuns na biossíntese das proteínas de Fe-S em todos os organismos, tal sugere a origem remota destes sistemas nos seres vivos e por isso não é de estranhar que a sua origem possa remontar aos primórdios da Vida na Terra.

\section{Das geociências às biociências - algumas hipóteses}

\section{Das razões para a escolha do $\mathrm{Fe}$ e $\mathrm{S}$ pelos organismos vivos}

A primeira questão que se põe é saber o porquê do Fe e do S participarem de forma relevante no metabolismo dos sistemas biológicos. Dos 90 elementos existentes na Terra de origem natural apenas cerca de 25 ocorrem nos organismos vivos e destes apenas um número mais restrito em todos os organismos. Dos que ocorrem em todos os seres vivos o Fe e o S são dois deles.

As razões para a escolha dos elementos são, em geral, pelo menos duas das seguintes: a Abundância (o Fe e o S são, respectivamente, o quarto e o décimo sétimo elementos mais abundantes na crusta terrestre [12]), a Disponibilidade (que duma maneira simples se refere à possibilidade dos elementos químicos serem solubilizados sem gastos de energia elevados ao serem incorporados no organismo) e a Eficiência Funcional [a aptidão para possibilitarem determinadas reacções (bio)químicas] [1]. Embora aqui já se esteja a referir aos organismos vivos e na actualidade muitos elementos sejam incorporados como compostos relativamente complexos, no período de transição entre os sistemas minerológicos e os biológicos a escoIha dos elementos teve certamente em conta as limitações da quantidade e da forma como se encontravam os materiais disponíveis, bem como a possibilidade das reacções em que participaram poderem dar continuidade ao processo que tornaria essas estruturas cada vez mais elaboradas, isto é, até terem atingido o nível em que pudessem ser consideradas como um ser vivo.

\footnotetext{
${ }^{3}$ Quem desejar aprofundar o assunto é conveniente consultar a referência [8]
} 


\section{Algumas Hipóteses para a Origem da Vida na Terra ${ }^{4}$}

Exemplos de hipóteses não envolvendo sistemas de Fe-S

Relativamente à origem da Vida na Terra não há unanimidade entre os cientistas e várias hipóteses têm sido colocadas. Alguns admitem que pode ter sido originada no cosmos, depois ter sido espalhada pelo Universo e desta forma ter chegado ao nosso planeta, enquanto outros consideram que a Terra teve condições especiais que permitiram a formação e o consequente desenvolvimento com sucesso dos organismos vivos [13].

Dentro das hipóteses que consideram que a Vida pode ter ser originada na Terra uma das possibilidades admitida é de que moléculas consideradas essenciais para a Vida se tenham formado e mais tarde se tenham agregado originando o que se pode considerar os primeiros organismos vivos. Esta hipótese tem como um dos seus fundamentos mais conhecidos a experiência efectuada por Miller[14], na qual este cientista aplicou descargas eléctricas numa atmosfera com características redutoras, com uma composição admitida para a atmosfera primordial da Terra, obtendo alguns aminoácidos correntes nos seres vivos. Esta hipótese tem tido alguma contestação no que se refere à composição da atmosfera primordial e da sua estabilidade, embora alguns ajustamentos feitos na composição não contrariassem de forma conclusiva os resultados obtidos anteriormente. Todavia, têm sido feitas outras críticas. Uma delas parte da verificação de que nas condições propostas as moléculas que se formam são uma mistura racémica e tal não se compagina com os sistemas biológicos que conhecemos nos quais os aminoácidos são predominantemente L. Uma outra põe em causa a forma como se pode ter efectuado a agregação das várias moléculas provenientes das reacções descritas, considerada pouco provável dada a concentração baixa dos produtos obtidos no meio em que foram gerados.

\section{Hipóteses envolvendo sistemas de Fe-S}

No final dos anos oitenta do século passado surgiram duas hipóteses que consideram que os minerais de Fe-S tiveram um contributo importante na formação das primeiras moléculas pré-bióticas.

Uma das hipóteses foi formulada por Wächtershäuser [15] e é designada por hipótese do mundo ferro-enxofre (do inglês, iron-sulfur world hypothesis) e a outra foi sugerida por Russell et al. [16] e é conhecida como a hipótese membranar ferro-enxofre (do inglês, ironsulfur membrane hypothesis). Ambas propõem que a vida emergiu como consequência de reacções químicas em meios fluídos redutores hidrotermais (na crusta e/ou no manto, por exemplo em zonas vulcânicas submarinas) em que participaram sulfuretos de metais de transição (predominantemente de Fe). Refira-se que os minerais que têm sido sugeridos como participantes nestas reacções são de origem magmática, metamórfica, e podem ocorrer em ambientes hidrotermais. Em ambas hipóteses é pressuposto que na fixação primitiva do carbono no processo de formação de moléculas orgânicas é mimetizado o designado ciclo redutivo do ácido cítrico ${ }^{5}$. Um outro aspecto relevante nas hipóteses que salientam a importância dos minerais contendo Fe e S na formação dos primeiros organismos vivos é o facto de considerarem que o metabolismo ocorreu primeiro e só numa fase mais tardia, em que a complexidade da estrutura já era maior, a componente codificadora (genética) começou a formar-se. Na verdade, um código, pela sua natureza, só pode codificar algo que já existe [1].
Na hipótese de Wächtershäuser a reacção primordial seria a formação de pirita e de dihidrogénio a partir de ácido sulfídrico e de monossulfureto ferroso (amorfo ou na forma de pirrotita):

$$
\mathrm{FeS}+\mathrm{H}_{2} \mathrm{~S} \rightarrow \mathrm{FeS}_{2}+\mathrm{H}_{2}
$$

No passo seguinte o dihidrogénio formado pode reagir com o dióxido de carbono dissolvido na água formando-se neste caso ácido fórmico, segundo a reacção:

$$
\mathrm{CO}_{2}(\mathrm{aq})+\mathrm{H}_{2} \rightarrow \mathrm{HCOOH}
$$

Refira-se que a reacção (1) é exergónica, mas a (2) é endergónica, todavia a reacção global de formação (3) é ainda exergónica e por isso este processo poderia ser possível.

$$
\begin{aligned}
& \mathrm{CO}_{2}(\mathrm{aq})+\mathrm{FeS}+\mathrm{H}_{2} \mathrm{~S} \rightarrow \\
& \rightarrow \mathrm{HCOOH}+\mathrm{FeS}_{2}
\end{aligned}
$$

Os óxidos de carbono permitiriam a produção de algumas moléculas orgânicas biológicas, as quais entrando no ciclo redutivo do ácido cítrico originariam novas moléculas. Nestes processos primordiais Wächtershäuser admite a formação de alguns compostos contendo enxofre por serem intermediários mais favorecidos do ponto de vista cinético [17].

Posteriormente, o mesmo autor tem publicado vários trabalhos sobre este tema e tem sido possível obter muitos compostos considerados fundamentais para a Vida na presença de sulfuretos de ferro, ver Fig. 4, e ainda de níquel e de cobalto [18]. Mais recentemente foi mesmo possível obter ácido pirúvico em condições baseadas nos pressupostos de Wächtershäuser [19]. Porém, nem todos os postulados admitidos por este autor foram ainda demonstrados, como seja o facto da reacção de formação da pirita ser a fonte de energia para terem sido geradas as primeiras moléculas pré-bióticas ${ }^{6}$, ver reacção (3). Esta hipótese tem tido contestação, ver por exemplo [20]. como a Hydrogenobacter thermophilus, e bactérias em que redução do sulfato é necessária ao seu metabolismo, como a Desulfobacter hydrogenophilus. Refira-se que o ciclo redutivo do ácido cítrico é um dos quatro mecanismos de fixação de dióxido de carbono e é admitido como sendo o mais antigo na escala da evolução.

6 Para mais pormenores ver a referência [17]. 


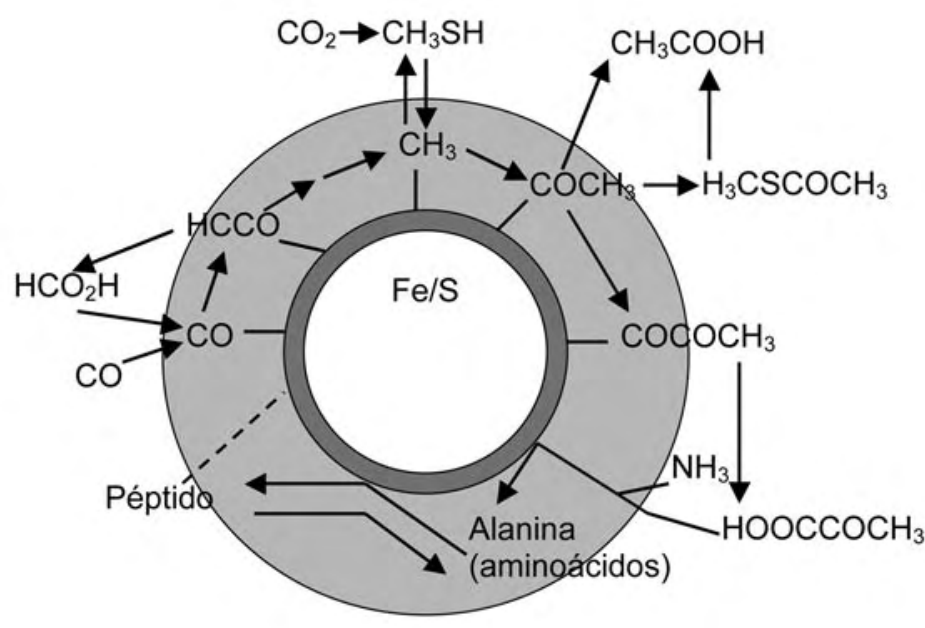

Figura 4 Representação de algumas reacções possíveis nos sistemas pré-bióticos segundo a hipótese de Wächtershäuser; estas reacções têm de se dar na presença de $\mathrm{CO}$ e $\mathrm{H}_{2} \mathrm{~S}$; não se incluíu a presença de Ni, nem de Co, ver texto; adaptada de [18]

Muitas das reacções primordiais implicam uma presença significativa de $\mathrm{H}_{2} \mathrm{~S}$ e pH ácido para garantir uma interacção forte entre as moléculas orgânicas aniónicas e a superfície da pirita. Na proposta de Wächtershäuser a pirita não actua apenas como um produto, mas participa nas reacções de formação das moléculas biológicas na sua superfície como consequência das afinidades diferenciadas desta por moléculas; tal pode favorecer a selectividade química e permitir a formação de sistemas mais complexos. Um exemplo é a possibilidade de síntese na superfície da pirita de macromoléculas biológicas a partir das unidades estruturais destas, reacção que num meio diluído não seria favorecida. A formação de peptidos a partir de aminoácidos permitiria a formação de moléculas que podem ser consideradas as primeiras enzimas (eventualmente metalo-enzimas que poderiam conter Fe). Este aumento de complexidade levaria, após vários desenvolvimentos, ao que seria um precursor de um organismo vivo. Está-se portanto perante uma hipótese que admite que houve uma evolução química, isto é, pré-biológica, o que antecipou a evolução biológica no sentido actual que conhecemos para as espécies.

A hipótese proposta por Russell et al. aponta para o início da Vida um sis- tema tipícamente geoquímico. Parte dos pressupostos que os primeiros oceanos eram quentes, cerca de $90^{\circ} \mathrm{C}$, com um $\mathrm{pH}$ de cerca de 5,5, com uma concentração de $\mathrm{CO}_{2}$ elevada (resultante do teor deste composto na atmosfera primitiva) e com teores significativos de $\mathrm{Fe}^{2+}$ e $\mathrm{Ni}^{2+}$ dissolvidos. Os autores admitem que fluídos hidrotermais penetraram no oceano, e dado que devido à sua temperatura (cerca de $150^{\circ} \mathrm{C}$ ) e ao seu $\mathrm{pH}$ básico (\9) seriam ricos em hidrogenossulfureto, dihidrogénio e conteriam ainda $\mathrm{NH}_{3}$, ao se misturarem com a água do mar poderiam originar a precipitação de sulfuretos de metais de transição (em especial ferro). Estes poderiam formar bolhas cuja superfície conteria sulfureto de ferro e serviria de membrana, a qual tem, ou teria, um carácter hidrófobo. Neste caso ter-se-ia um sistema com um $\mathrm{pH}$ baixo no exterior da membrana e no interior um valor mais elevado, bem como um ambiente mais redutor neste relativamente ao exterior. Os gradientes de $\mathrm{pH}$ e de potencial favoreceriam a transferência electrónica e a entrada de dióxido de carbono (ou hidrogenocarbonato) para o interior do sistema, podendo desta forma dar-se a síntese de moléculas orgânicas [21]. O seu aumento de grau de complexidade seguiria um percurso com analogias ao da hipótese de Wächtershäuser.
Entre ambas as propostas as diferenças mais significativas referem-se ao facto de que Wächtershäuser considera que a formação da pirita é essencial como fonte de energia e ainda como centro catalítico, enquanto que na proposta de Russell et al. a formação de uma membrana é fundamental para todo o processo. Nesta proposta os minerais sugeridos são a greigita e a violarita por terem uma estrutura que tem analogias com o agregado de Fe-S das ferredoxinas "tipo bactéria" $\mathrm{Fe}_{4} \mathrm{~S}_{4}$, ver Fig.1 em baixo, tão importantes em processos metabólicos [17].

Ainda relativamente a violarita, que é também um mineral de Ni, é de salientar também uma enzima que ocorre em organismos unicelulares, que usa dihidrogénio ou o hidrogenião como substrato e pode conter um agregado de Fe-S ou de Fe-Ni-S, ver Fig. 3 [22]. Refira-se que a atmosfera primitiva terrestre era redutora e deve ter contido algum dihidrogénio na sua composição [23], o que pode sugerir a importância de outros elementos nas sínteses pré-bióticas.

\section{Conclusões}

Os elementos químicos são fundamentais em todo o tipo de estruturas que existem na Terra (e no Universo), incluindo os organismos vivos que são estruturas organizadas e complexas que necessitam de componentes adequados para a sua sobrevivência. A sua formação e desenvolvimento passaram por processos de evolução complexos, mas alguns elementos tiveram um papel relevante. Entre os elementos que sabemos serem necessários para a manutenção de um organismo vivo, o Fe e o S, podem ter dado contributos importantes desde os primórdios na formação dos compostos pré-bióticos. Como razões podem salientar-se no ambiente primitivo da Terra a relativa abundância de sulfuretos (consequência da Terra ter nesse período uma atmosfera com características redutoras) em que os de Fe seriam relevantes, dada a abundância deste elemento, e as potencialidades catalíticas dos minerais formados por estes dois elementos. Um possível vestígio actual desta participação pode ser a grande importância que as proteínas 
de Fe-S têm nos organismos actuais. Duas hipóteses foram formuladas para justificar as reacções iniciais a partir de minerais, a de Russell com maior carácter teórico-especulativo, enquanto a de Wächtershäuser tenta mimetizar reacções que se julgam promordiais. A demonstração cabal destas possibilidades não pode ser feita na actualidade. Por isso, um melhor conhecimento da química dos sulfuretos, permitirá aplicações em domínios científicos diferentes e certamente poderá dar novas pistas e uma maior sustentabilidade sobre a sua possível participação na química pré-biótica, e desta forma indicar a possibilidade de áreas científicas relacionadas com a geologia e a biologia estarem bem mais próximas e o seu elo de ligação ser a química.

\section{Agradecimentos}

Ao Professor J. J. R. Fraústo da Silva pelo leitura crítica do manuscrito e ao avaliador anónimo por alguns comentários pertinentes que fez.

\section{Referências}

[1] J. J. R. Fraústo da Silva, R. P. J. Williams, The Biological Chemistry of the
Elements - the inorganic chemistry of

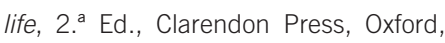
2001.

[2] http://un2sg4.unige.ch/athena/mine$\mathrm{ral} / \mathrm{minppcl} 2 . \mathrm{html}$ (acedido em 11-052006).

[3] D. A. Bazylinski, R. B. Frankel, Nature Reviews Microbiology 2 (2004) 217-230.

[4] A. Waren, S. Bengtson, S. K. Goffredi, C. L. Van Dover, Science 302 (2003) 1007-1007.

[5] P. V. Rao, R. H. Holm, Chemical Reviews 104 (2004) 5277-559.

[6] J. Frazzon, D. R. Dean, Current Opinion in Chemical Biology 7 (2003) 166-173.

[7] O. A. Lukianova, S. S. David, Current Opinion in Chemical Biology 9 (2005), 145-151.

[8] D. C. Johnson, D. R. Dean, A. D. Smith, M. K. Johnson, Annual Review of Biochemistry 74 (2005) 247-281.

[9] J. Gerber, R. Lill R, Mitochondrion 2 (2002) 71-86.

[10] J. Balk J, S. Lobréaux, Trends in Plant Science 10 (2005) 324-331.

[11] J. Tovar, G. León-Avila, L. B. Sánchez, R. Sutak, J. Tachezy, M. van der Giezen, M. Hernández, M. Müller, J. M. Lucocq, Nature 426 (2003) 172-176.
[12] J. Emsley, The Elements, 2. . Ed., Clarendon Press, Oxford, 1994.

[13] D. Penny, Biology and Philosophy 20 (2005) 633-671.

[14] S. L. Miller, Science 117 (1953) 528529.

[15] G. Wächtershäuser, Microbiological Reviews 52 (1988) 452-484.

[16] M. J. Russell, A. J. Hall, A. G. Cairnssmith, P. S. Braterman, Nature 336 (1988) 117-117.

[17] G. D. Cody, Annual Review of Earth Planetary Sciences 32 (2004) 569-599.

[18] G. Wächtershäuser, Science 289 (2000) 1307-1308.

[19] G. D. Cody, N. Z. Boctor, T. R. Filley, R. M. Hazen, J. H. Scott, A. Sharma, H. S. Yoder, Science 289 (2000) 1337-1340.

[20] A. Lazcano, S. L. Miller, Cell 85 (1996) 793-798.

[21] M. J. Russell, A. J. Hall, Journal of the Geological Society, London 154 (1997) 377-402.

[22] F. A. Armstrong, Current Opinion in Chemical Biology 8 (2004) 133-140.

[23] F. Tian, O. B. Toon, A. A. Pavlov, H. De Sterck, Science 308 (2005) 1014-1017.

\section{O Caso de Peso da Gordura}

Os apreciadores de manteiga de todo o mundo irão gostar de saber que aparentemente existe uma boa razão para recusarem a margarina. De acordo com investigadores da Universidade de Wake Forest, os ácidos gordos trans detectados nas margarinas e em produtos oleaginosos derivados podem conduzir a ganhos de peso. Os investigadores sugerem que o formato corporal tipo maçã, geralmente associado a um risco aumentado de diabetes e problemas cardíacos, pode ser acelerado pela ingestão de ácidos gordos trans, que incluem os óleos vegetais parcialmente hidrogenados presentes na margarina.

Lawrence Rudel explica que "Dietas ricas em ácidos gordos trans induzem uma redistribuição da matéria gorda para o abdómen e levam a um aumento do peso corporal mesmo que as calorias totais ingeridas sejam controladas".

Nos últimos anos tem subido a preocupação acerca dos efeitos dos ácidos gordos trans na saúde, em comparação com os óleos mono-insaturados, como os encontrados no azeite. A Food and Drug Administration (FDA, EUA) afirma que a ingestão de gorduras saturadas, ácidos gordos trans e colesterol provocam um aumento da concentração de lipoproteínas de baixa densidade (LDL ou colesterol "mau") no corpo, o que está intimamente relacionado com um risco aumentado de doenças coronárias.

Kylie Kavanagh apresentou as conclusões da equipa de investigação nas 66 . as Sessões Científicas anuais da Associação Americana de Diabetes em Washington, DC. Durante seis anos, em macacos alimentados com uma dieta contendo ácidos gordos trans, observou-se um aumento de $7.2 \%$ no peso corporal. Por outro lado, o aumento observado em macacos que ingeriram gorduras mono-insaturadas foi de apenas $1.8 \%$. Os investigadores observaram, através do uso de tomografia computorizada, que o peso extra se devia à acumulação na região do abdómen e que mesmo a gordura distribuída noutras regiões do corpo era transferida para essa zona. Kavanagh afirma que "não esperavam que os macacos se tornassem obesos, já que não Ihes tinham fornecido calorias suficientes para tal, mas as análises provaram o contrário para os que foram alimentados com ácidos gordos trans, o que indicia que o seu consumo provoca realmente um aumento de peso". (adaptado de webzine Reactive Reports 56, 2006).

Paulo Brito 